\title{
MASCULINIDAD Y SUICIDIO. CONEXIONES Y POSIBILIDADES DE TRANSFORMACIÓN DESDE LA TERAPIA NARRATIVA Y EL TEATRO DEL OPRIMIDO
}

\author{
Masculinity and Suicide. Connections and possibilities of transformation \\ from narrative therapy and the theater of the oppressed
}

\author{
JHOAN SEBASTIÁN APONTE-GONZÁLEZ* \& DIANA LAVERDE**
}

Fecha de recepción: 29 de septiembre de 2020 - Fecha de aprobación: 28 de junio de 2021

\section{Resumen:}

Este estudio tuvo como propósito general comprender la configuración narrativa de la relación entre masculinidad y conducta suicida para movilizarla a través de elementos del teatro del oprimido y la terapia narrativa hacia un devenir de re-existencia y desideologización. Se realizó un estudio de caso único con un hombre de 22 años a través de una estrategia en la que se articularon los elementos mencionados. Entre las conclusiones generales, se destaca una narrativa en la que el participante veía al suicidio como única forma de escapar del sufrimiento generado por la masculinidad hegemónica. Asimismo, se resaltan las posibilidades que generan las articulaciones presentes en la estrategia para comprender y transformar dicha narrativa. Este estudio permite ver la importancia de la perspectiva de género y el teatro del oprimido en el abordaje del suicidio.

Palabras clave: suicidio, masculinidad, teatro del oprimido, terapia narrativa, re-existencia, desideologización.

\section{Abstract:}

The general purpose of this study was to understand the narrative configuration of the relationship between masculinity and suicidal behavior to mobilize it through elements of theater of the oppressed and narrative therapy towards a becoming of re-existence and de-ideologization. A unique case study was carried out with a 22-year-old man, through a strategy in which elements of narrative therapy were articulated with the theater of the oppressed. Among the general conclusions, a narrative stands out in which for the participant the only way to escape the suffering generated by hegemonic masculinity was suicide. Likewise, the possibilities generated by the articulations present in the strategy to understand and transform said narrative are highlighted. This study allows us to see the importance of the gender perspective and the theater of the oppressed in the intervention of suicide.

Keywords: suicide, masculinity, theater of the oppressed, narrative therapy, re-existence, de-ideologization.

\footnotetext{
* Mg. en Psicología Clínica y de la Familia. Estudiante del Máster Universitario en Estudios Culturales y Artes Visuales (Perspectivas Feministas y Cuir/Queer), Universidad Miguel Hernández de Elche, España. El artículo se encuentra enmarcado en la tesis de magíster Conexión entre suicidio y masculinidad. Una mirada desde la terapia narrativa y el teatro del oprimido. Correo-e: jhoanaponte@usantotomas.edu.co

** Mg. en Psicología Clínica y de la Familia. Docente de la Maestría en Psicología Clínica y de la Familia, Universidad Santo Tomás, Colombia. Correo-e: dianalaverde@usantotomas.edu.co
} 


\section{Introducción}

La conducta suicida es un fenómeno de gran relevancia para la salud pública por el riesgo que supone para la vida de quien la experimenta. De acuerdo con Hunt (2019), la Organización Mundial de la Salud (OMS) reporta que anualmente en el mundo se suicidan 800.000 personas. Menciona, asimismo, que se dan 13,7 muertes por suicidio en cada 100.000 hombres y 7,5 en cada 100.000 mujeres. Cuando se contrasta esta información con los datos colombianos, esta marcada diferencia entre hombres y mujeres se mantiene. En 2019, murieron en Colombia 2.550 personas en total por esta causa, distribuidas en 2.032 hombres y 518 mujeres (Instituto Nacional de Medicina Legal y Ciencias Forenses, 2019). Estos datos internacionales y nacionales invitan a profundizar en las implicaciones que tiene el género en la conducta suicida.

La conexión entre salud mental y género ha sido explorada por investigaciones como las de Díaz, Rivera \& Wolfgand (2012), Budge y Moradi (2018), Maguen, Ren, Bosch, Marmar \& Seal (2010), Paguey (2017) y Schermer (2013). Estos estudios reconocen que la aparición de trastornos de salud mental parece estar ligada al género, desde una noción de salud mental ligada a lo psicopatológico y una perspectiva de género binaria que solo reconoce a hombres y mujeres. Al contrario, investigaciones como las de Charry \& Pedraza (2019), Llanos \& Saavedra (2019), Lodoño, Mendivelso \& Rodríguez (2017) y Planas (2018) retoman el género desde la multiplicidad de posibilidades en su configuración, partiendo además de una comprensión relacional de la salud mental que va más allá de lo psicopatológico. Estos trabajos destacan que las configuraciones de género y su emergencia en el escenario interventivo no solo pueden ser vistas desde lo deficitario, sino desde lo generativo.

Tal como lo exponen las cifras presentadas, uno de los fenómenos de salud mental que parece tener mayor prevalencia en hombres es el de la muerte por suicidio. Dicha relación ha sido explorada en investigaciones como las de Rosado, García, Alfeo \& Rodríguez (2014), Pirkis, Spittal, Keogh, Mousaferiadis \& Currier (2017) y Apesoa-Verano, Barker \& Hinton (2018), mismas que coinciden en afirmar que la masculinidad suele ser vista como un factor de riesgo que contribuye con la aparición, el mantenimiento y el agravamiento de la conducta suicida. Los rasgos de masculinidad que aparecen con mayor frecuencia en estas investigaciones son la no expresión emocional (especialmente de emociones como la tristeza y el fracaso) y la autosuficiencia (la búsqueda de los hombres de mostrarse fuertes e independientes). Así, estos estudios invitan a reconocer la pertinencia de tener en cuenta el género al momento de abordar casos relacionados con suicidio.

En coherencia con esto, un elemento que puede resultar potente para la investigación y la intervención en el género es el teatro del oprimido, ya que investigaciones como las de Madurga \& Serra (2016), Spychaj (2014), Porras (2016), Parra (2015), Biggus (2017) y Cárdenas y Pozo (2018) exponen que desde la reflexión que se hace de la opresión y la activación de lo sensible desde el cuerpo se pueden generar espacios en los que se cuestionen los roles, mandatos y relaciones que se configuran alrededor del género, lo que permite a las personas, desde ejercicios teatrales, ampliar su comprensión sobre sí mismas y cómo se posicionan frente a estas construcciones sociales. 
Teniendo esto en cuenta, el presente estudio se enfoca en la configuración narrativa de la conexión entre la masculinidad y el suicidio desde una apuesta de investigación-intervención que retoma la indagación sobre la opresión y el cuerpo desde el teatro del oprimido, así como las comprensiones de la configuración del sufrimiento desde la terapia narrativa. Adicionalmente, se tuvieron en cuenta las posibilidades de comprender el cambio que ofrecen los conceptos de desideologización y re-existencia. De este modo, se busca responder a la siguiente pregunta: ¿cómo se configura y moviliza narrativamente la relación entre masculinidad y suicidio en un devenir de desideologización y re-existencia a partir de la articulación del teatro del oprimido y la terapia narrativa?

Para responder a esta pregunta, este estudio definió como objetivo general la comprensión de la configuración narrativa de la relación entre masculinidad y conducta suicida para movilizarla a través de elementos del teatro del oprimido y la terapia narrativa hacia un devenir de re-existencia y desideologización. A partir de este lineamiento principal se definieron dos objetivos específicos: 1) explorar la relación entre las narrativas de masculinidad y las narrativas alrededor de la conducta suicida para develar posibilidades de transformación de dicha relación, y 2) posibilitar, desde el engranaje de elementos del teatro del oprimido y de la terapia narrativa, procesos de desideologización y la emergencia de narrativas de re-existencia en la vida y la masculinidad para favorecer mayores niveles de bienestar, autonomía y libertad. Por último, desde la problematización realizada, la pregunta y los objetivos definidos, se planteó la siguiente hipótesis de trabajo: el suicidio puede configurarse como una opción para detener el sufrimiento por una vida que no se siente como propia y un intento por proteger o recuperar una masculinidad fragmentada por el fracaso frente a las historias dominantes de la misma. Frente a esto, la articulación del teatro del oprimido y la terapia narrativa puede favorecer un devenir de desideologización y re-existencia al permitir la emergencia de nuevas formas de ser, estar y relacionarse en el mundo que cuestionan y redefinen la vivencia de las historias dominantes de la masculinidad, aumentando así la autonomía en la definición del curso de la vida desde el querer ser y no el deber ser.

\section{Referentes epistemológicos y teóricos}

Epistemológicamente este estudio se configuró desde las ciencias de la complejidad, el construccionismo social, las cibernéticas y la teoría queer.

De las ciencias de la complejidad se asumió la apuesta, descrita por autores como Osorio (2012) y Maldonado \& Gómez (2010), de trabajar con la pluralidad, la diversidad y la alteridad para abrir, desde lecturas no lineales, posibilidades de ver relaciones donde normalmente no son vistas. Este posicionamiento epistemológico supuso abandonar nociones deterministas y lineales para comprender el suicidio, e invitó a una mirada centrada en la multicausalidad desde la cual se exploró de manera novedosa la relación entre suicidio y masculinidad.

Desde el construccionismo social, se partió de la noción expuesta por autores como Gergen (2007) y Agudelo-Bedoya \& Estra- 
da-Arango (2012) de que los conceptos que definen el mundo y la mente están integrados al lenguaje, por lo que son constitutivos de las practicas discursivas y se encuentran sujetos a negociación. Esto supuso, en este proceso de investigación, una apuesta centrada en el reconocimiento de cómo las narrativas y las relaciones configuraban las realidades de sufrimiento del participante que lo conectaban con el suicidio, así como una apuesta para acompañar en la creación de escenarios de posibilidad.

De la mano con lo anteriormente expuesto, para la configuración de esta investigación fue crucial, en términos epistemológicos, los diferentes órdenes de la cibernética, que "para Bateson (1972) es la nueva ciencia de la forma y los patrones de organización, para Keeney (1987) es una ciencia que se ocupa de las pautas y la organización en los diferentes tipos de sistemas" (Camacho, 2006, p. 6). De acuerdo con Mancilla (2011), la cibernética puede ser comprendida en tres órdenes: la de primer orden trata los sistemas observados; la de segundo orden, los sistemas observantes; la de tercer orden, los sistemas mutuamente observantes. Incluso, en un artículo posterior, Mancilla (2013) suma a su teoría de los órdenes de la cibernética una cibernética de cuarto orden, que trata los sistemas auto-observantes. Estos diferentes órdenes de la cibernética fueron centrales durante la investigación, ya que ponen de manifiesto no solo la importancia de reconocer las formas en las que se construye el conocimiento, sino los diferentes sistemas de observación y lugares que tuvieron en este proceso, algo que se rastreó durante todo el desarrollo investigativo.

Por último, se retomaron dos ideas centrales de la teoría queer: la primera, expuesta por
Vila (2018), la postura de explorar los distintos niveles de exclusión que se dan en los procesos de construcciones identitarias (especialmente atravesadas por el género) en diferentes contextos, para escapar de las lógicas binarias; y la segunda, enunciada por Fonseca \& Quintero (2009), el llamado a configurar un constante devenir de deconstrucción de lo considerado como normativo y de los lugares de segregación que desde allí se generan en lógicas de centros (lo normativo) y periferias (lo no normativo). Esta perspectiva supuso una mirada crítica frente a las relaciones de poder que atraviesan la masculinidad, así como una invitación a reconocer la multiplicidad de posibilidades de agenciamiento que se puede dar desde las configuraciones de género para hacer frente a las imposiciones de lo normativo.

\section{Explorando el fenómeno: suicidio y masculinidad}

Una vez expuestos los referentes epistemológicos de esta investigación, es importante explicitar cuáles fueron las comprensiones alrededor del suicidio y la masculinidad, así como las conexiones entre ambos que orientaron este estudio.

En lo referente al suicidio, autores como Durkheim (2012) y Klonsky, May \& Saffer (2016) lo comprenden como la muerte ocasionada por acciones u omisiones (incluyendo ideas y planes) perjudiciales y dañinas dirigidas a sí mismo con la intención de morir. Este hecho no puede ser visto desde un único factor, ya que, como lo expone Andrade (2016), "el suicidio es un fenómeno complejo porque su emergencia requiere la interacción simultánea entre aspectos ambientales, genético-cerebromoti- 
vacionales, bricolajes existenciales e imprinting socioculturales" (p. 22). Este fenómeno es, por tanto, una manifestación de las interacciones de una serie de factores que posicionan la muerte como opción sobre la vida. Adicionalmente, autores como Rodríguez (2017) y Lemus \& Vargas (2016) exponen que el suicidio puede ser visto como una metáfora que da cuenta de la fragmentación de las relaciones, así como una posibilidad para la reorganización de los sistemas relacionales.

En la lectura compleja que Andrade (2016) hace del suicido son particularmente relevantes las conexiones que hace con los principios hologramático y dialógico. Para este autor, ver el suicidio desde el principio hologramático implica que cada pensamiento, intento o acción suicida contiene en sí misma la globalidad de la acción destructiva y el incremento tanto motivacional como comportamental hasta la autodestrucción. Cada evento contiene al suicidio como globalidad, directa o indirectamente. El suicidio es la eliminación de la complejidad del sistema, en otras palabras, su autodestrucción y muerte.

Para Andrade (2016), desde el principio dialógico el suicidio da lugar a la emergencia de nuevas oportunidades de comprensión sobre la vida y la existencia, las cuales pueden tanto incentivar a la persona a quitarse la vida como a construir acciones protectoras de la misma. Según este autor, en el primer caso existen ambivalencias extremas relacionadas con el valor de la vida, al mismo tiempo que se presentan motivaciones, explicaciones y objetivos para la misma, que incluso siendo contrarios, pueden convertirse en un núcleo perceptivo que aprueba las conductas suicidas, mientras que para que lo segundo ocurra es de vital importancia que se tenga la capacidad de establecer conexiones entre los motivos para vivir, el futuro y los elementos protectores. Lo que induce a la vida y lo que incita a la muerte tienen un carácter reticular, pero con una gran emergencia que los diferencia: la vida perpetúa el sistema, lo invita a trascender el reconocimiento de sí mismo y del otro, mientras que la muerte termina con el sistema y sus interacciones.

En cuanto a la masculinidad, esta se comprende como una construcción histórica y cultural que hace alusión a los mecanismos que definen lo que es ser hombre, por lo que su comprensión variará de acuerdo con la época y el contexto histórico (Infantes \& Delgado, 2011; Jabeen, 2018). Esta postura invita a no hablar de masculinidad, sino de masculinidades, para reconocer la pluralidad y la diversidad de comprensiones que esta puede tener. Una de esas comprensiones es la de la masculinidad hegemónica que, de acuerdo con Connell (2005), se puede definir como una manera concreta de expresar el género masculino que aporta legitimidad al patriarcado al garantizar la posición dominante de los hombres y la subordinación de las mujeres. Este orden patriarcal "prohíbe ciertas formas de emoción, afecto y placer que la propia sociedad patriarcal produce" (Connell, 1995, p. 20). De este modo, la masculinidad hegemónica tiene como referentes: "homofobia, misoginia, poder, estatus y riqueza, sexualidad desconectada, fuerza y agresión, restricción de emociones e independencia y autosuficiencia" (Infantes \& Delgado, 2011, p. 96).

En este mismo contexto, Connnel (1995) señala que hay relaciones de género de dominación y subordinación entre grupos de hombres. Para el autor, las masculinidades subordinadas son aquellas confinadas a los guetos y que se relacionan con los hombres gays que suelen ser 
discriminados; en tanto, para la masculinidad hegemónica, estos se asimilan con la feminidad. No obstante, Carabí \& Armengol (2015) exponen que esta noción de masculinidad hegemónica se ha ido reconceptualizando y siendo reconocida como un ejercicio del que participan varios colectivos (incluso los que se consideran subordinados) para mantener el patriarcado. Asimismo, estos autores resaltan la importancia de reconocer las masculinidades alternativas más allá de la subordinación a la masculinidad hegemónica desde la cual estas eran vistas en conceptualizaciones iniciales, lo que ha dado lugar a ver en estas masculinidades alternativas nuevas posibilidades de ser y vivir como hombre. Esto se conecta con lo que García (2015) enuncia como nuevas masculinidades, las cuales son prácticas vivenciales en niveles personales, comunitarios y estructurales del ser hombre asumiendo un posicionamiento crítico y distante frente a los valores del patriarcado.

Sin embargo, es importante reconocer que tanto la masculinidad hegemónica o las nuevas masculinidades (o masculinidades alternativas) no son entidades estáticas o que deban verse como "buenas" o "malas", ya que, tal como lo expone Horlacher (2015), el género puede ser considerado una ficción regulatoria, una narrativa que tiene diferentes formas en diferentes tiempos y contextos, caracterizada por cierta fluidez o inestabilidad, lo que da lugar a negociaciones, cambios y mutabilidad, sin que esto desestime el sustrato biológico o las preguntas por el cuerpo.

Teniendo en cuenta la conceptualización referida de suicidio y masculinidad, resulta interesante retomar dos teorías alrededor de la conexión de estos dos fenómenos. Por un lado, Lynberg, Haavind \& Dieserud (2018) exponen que el suicidio en hombres se puede ver como un acto característico de la masculinidad compensatoria, es decir, que el suicidio es percibido por los hombres como la única alternativa para solucionar los problemas, así como una acción que permite recuperar su masculinidad fragmentada por la debilidad y el fracaso, mostrándose a sí mismos de manera heroica al no culpar a nadie más por sus problemas y asumir toda la responsabilidad por sus fracasos y dándoles solución al quitarse la vida. Mientras que Jordan \& Chandler (2019) exponen que el suicidio masculino da cuenta de una crisis de la masculinidad, que puede ser entendida desde una narrativa conservadora (en la que la masculinidad, sus normas y roles tradicionales de género se ven amenazados por los cambios sociales, y que, por tanto, hay que volver a ellos) y una narrativa progresista (en la que se reconoce que las configuraciones tradicionales de género causan daño tanto a hombres como a mujeres y que es necesario su transformación). En este proceso de investigación se trabajó con la narrativa progresista de la crisis de la masculinidad, ya que se exploraron aquellos relatos hegemónicos que suponían un malestar en el participante, así como se buscaron transformar dichos relatos a partir de la estrategia metodológica.

\section{Articulación para el cambio: terapia narra- tiva, teatro del oprimido, desideologización y re-existencia}

Una vez expuestas las comprensiones que orientaron esta investigación en torno a la masculinidad y el suicidio y sus posibles conexiones, es necesario conceptualizar los elementos que permitieron desarrollar la estrategia para comprender el fenómeno y transformarlo. El 
primer elemento fue la terapia narrativa que, de acuerdo con autores como White (2007) y Latorre (2013), se centra en la importancia de la construcción de significados en las historias contadas por las personas para ordenar su experiencia vivida. Estas historias pueden suponer sufrimiento $y$, frente a ellas, desde la terapia narrativa, se busca construir nuevos significados y ampliar la identidad a partir de prácticas terapéuticas que favorecen la narración y la renarración, haciendo visibles otras historias, asociadas con nuevas maneras de construir la identidad y las acciones que se conectan más con lo que las personas consideran como valioso.

Dentro de las apuestas de la terapia narrativa expuestas por Payne (2002), esta investigación se centró en tres: 1) la deconstrucción de enlaces inesperados, en la que se buscan aquellas experiencias y relatos que escapan a la historia dominante y se les trata de llenar de detalles y mayor fuerza narrativa; 2) el tener en cuenta los aspectos sociales y políticos de la narrativa como un reconocimiento de que las historias que cuentan las personas no se dan en el vacío, sino que tienen relación con discursos y prácticas sociales; y 3) la indagación de la influencia relativa, en la que después de un proceso de externalización, que permite separar al problema de la identidad de la persona, se invita a ver cómo el problema ha influido en su vida y viceversa.

El segundo elemento para la configuración de la estrategia fue el teatro del oprimido, el cual, según Boal (2013), es un sistema de ejercicios físicos y estéticos que, a través de la actividad teatral, busca comprender y solucionar los problemas sociales y transformar las relaciones de opresión que los configuran. El teatro del oprimido tiene cuatro pilares: artístico, educativo, político-social y terapéutico. Según este autor, el "arcoíris del deseo" responde al cuarto pilar y busca, desde el teatro, "analizar los colores de nuestros deseos y voluntades, para armonizarlos de manera diferente, con otras proporciones, con otras formas y en otros lienzos más acordes con nuestra felicidad" (p. 29).

Boal (2013) expone tres hipótesis que son centrales para el arcoíris del deseo: 1) la osmosis, que propone que en cada persona y su vida se encuentran contenidas todas las estructuras de dominación, poder y opresión de la sociedad; 2) la metaxis, que supone invitar al participante a reconocer que se encuentra en dos mundo al mismo tiempo: la realidad social que vive en su cotidianidad y la recreación que hace de esa realidad en la escena teatral; y 3) la inducción analógica, que invita a ofrecer múltiples versiones y puntos de vista para un análisis distanciado y más amplio de las realidades sociales vividas por los participantes.

Por último, la desideologización y la re-existencia fueron los conceptos que permitieron comprender el proceso de cambio. Según Ignacio Martín-Baró (1990), la desideologización es comprendida como un proceso que busca desenmascarar aquel "sentido común" que hace posible y legitima la opresión. Mientras que la re-existencia, según Ríos (2015), se diferencia de la resistencia en cuanto que no supone resistir una fuerza con otra que le resulte contraria, sino que busca decodificar los significados de esa fuerza que resulta opresiva para generar un nuevo orden de sentido en el que se dé lugar a nuevas posibilidades existenciales que tengan mayor sintonía con la propia subjetividad. La re-existencia, entonces, busca descentrar las lógicas establecidas, para así buscar nuevas claves de producción y organi- 
zación, que permitan dignificar y transformar la vida (Achinte, 2009).

\section{Método}

Esta investigación fue de corte cualitativo, lo que, retomando a González (2006), supone comprender el quehacer investigativo como un ejercicio dialógico e interpretativo en el que la voz de los participantes tiene un lugar protagónico, al mismo tiempo que se reconoce que el conocimiento no es neutral ni ajeno a quien lo produce. Teniendo en cuenta lo anterior, se asumió el enfoque de investigación-intervención, el cual parte de la premisa de que no existen acciones investigativas que no tengan efectos interventivos, ni viceversa (Estupiñán, González \& Serna, 2006). Es decir, tratar de comprender un fenómeno supone transformaciones en el mismo y dichas transformaciones abren nuevas posibilidades comprensivas, por lo que el rol que fue asumido en esta investigación fue el de investigador-interventor. Este enfoque se conectó con la investigación basada en el arte que, tal como lo exponen Baden \& Wimpenny (2014), hace uso del proceso artístico como una forma de comprender los fenómenos sociales, yuxtaponiendo el arte y la investigación para explorar y transformar la experiencia.

Se realizó un estudio de caso configurado por la teoría que, según Scandar (2014), es cuando el investigador, desde la teoría, diseña un análisis riguroso, detallado y profundo de una unidad de análisis con coordenadas temporales y espaciales definidas, y define la recolección de datos y modelos explicativos del mismo. Como lo exponen Rodríguez, Gil \& García (2006), existe un debate entre diferentes autores sobre si el estudio de caso es un método o una estrategia, pero al igual que los autores mencionados, esta investigación asumió el estudio de caso como una estrategia que permite explorar la pregunta orientadora. Se diseñaron, así, cinco escenarios de investigación que articulan el teatro del oprimido y la terapia narrativa. Los focos, actores, técnicas y dispositivos terapéuticos utilizados en estos escenarios se presentan en la Tabla 1. 
Tabla 1. Escenarios de investigación-intervención.

\begin{tabular}{|c|c|c|c|}
\hline Escenario & Foco & Actores & Dispositivos terapéuticos \\
\hline $\begin{array}{l}\text { El amor en los } \\
\text { tiempos de la } \\
\text { heteronorma }\end{array}$ & $\begin{array}{l}\text { Vivencias } \\
\text { alrededor de la } \\
\text { masculinidad y } \\
\text { el suicidio }\end{array}$ & $\begin{array}{l}\text { Participante } \\
\text { Investigador- } \\
\text { interventor }\end{array}$ & $\begin{array}{l}\text { Elaboración de una máscara dividida } \\
\text { en dos partes: la primera, en la que el } \\
\text { participante representó su experiencia } \\
\text { de masculinidad, y la segunda, en la } \\
\text { que representó su experiencia con el } \\
\text { deseo de morir. }\end{array}$ \\
\hline $\begin{array}{l}\text { La insoporta- } \\
\text { ble rigidez del } \\
\text { macho }\end{array}$ & $\begin{array}{l}\text { Mandatos } \\
\text { sociales y } \\
\text { deseos sobre } \\
\text { masculinidad } \\
\text { y vida }\end{array}$ & $\begin{array}{l}\text { Participante } \\
\text { Investigador- } \\
\text { interventor }\end{array}$ & $\begin{array}{l}\text { El participante realizó cuatro imágenes } \\
\text { corporales (con su cuerpo y objetos } \\
\text { del espacio): dos que representaron el } \\
\text { deber ser de la masculinidad y la vida } \\
\text { y dos que representaron sus deseos } \\
\text { (querer ser) sobre estos dos focos. }\end{array}$ \\
\hline $\begin{array}{l}\text { Sobre los } \\
\text { huesos de los } \\
\text { vivos }\end{array}$ & $\begin{array}{l}\text { Resiliencia y } \\
\text { resistencia en } \\
\text { la masculini- } \\
\text { dad y la vida }\end{array}$ & $\begin{array}{l}\text { Participante } \\
\text { Meta- } \\
\text { observadoras } \\
\text { Investigador- } \\
\text { interventor }\end{array}$ & $\begin{array}{l}\text { Se partió del ejercicio escritural de la } \\
\text { anterior sesión sobre lo vivido en ella. } \\
\text { El participante realizó dos imágenes } \\
\text { corporales (con su cuerpo, objetos del } \\
\text { espacio y el cuerpo del investigador-in- } \\
\text { terventor) para explorar lo que ha sido } \\
\text { la resiliencia y la resistencia en su vida. } \\
\text { Se retomaron las imágenes corporales } \\
\text { de la anterior sesión (el investiga- } \\
\text { dor-interventor las dibujó antes de la } \\
\text { sesión) y el participante las intervino } \\
\text { con colores y dibujos para representar } \\
\text { la resistencia y la resiliencia frente a la } \\
\text { masculinidad y la vida. } \\
\text { Se cerró la sesión escuchando el análi- } \\
\text { sis de lo ocurrido en la sesión de las } \\
\text { meta-observadoras. }\end{array}$ \\
\hline
\end{tabular}




\begin{tabular}{|c|c|c|c|}
\hline Escenario & Foco & Actores & Dispositivos terapéuticos \\
\hline $\begin{array}{l}\text { Ser y } \\
\text { sensibilidad }\end{array}$ & $\begin{array}{l}\text { Re-existencia } \\
\text { y desideolo- } \\
\text { gización en la } \\
\text { masculinidad y } \\
\text { la vida }\end{array}$ & $\begin{array}{l}\text { Participante } \\
\text { Investigador } \\
\text {-interventor }\end{array}$ & $\begin{array}{l}\text { Se retomó el ejercicio escritural sobre } \\
\text { lo que el participante pensó de lo dicho } \\
\text { por las meta-observadoras en la ante- } \\
\text { rior sesión. } \\
\text { El participante escribió y declamó en } \\
\text { la sesión un monólogo que recogió los } \\
\text { nuevos lugares de existencia que ha } \\
\text { venido descubriendo y construyendo a } \\
\text { partir del proceso que se viene adelan- } \\
\text { tando. }\end{array}$ \\
\hline $\begin{array}{l}\text { El matrimonio } \\
\text { entre la vida y } \\
\text { la muerte }\end{array}$ & $\begin{array}{l}\text { Nuevas posi- } \\
\text { bilidades exis- } \\
\text { tenciales }\end{array}$ & $\begin{array}{l}\text { Participante } \\
\text { Investigador-in- } \\
\text { terventor } \\
\text { Voces de perso- } \\
\text { nas significativas }\end{array}$ & $\begin{array}{l}\text { La sesión inició recuperando en un ejer- } \\
\text { cicio escritural la experiencia de decla- } \\
\text { mar el monólogo en la sesión anterior. } \\
\text { El participante tomó diferentes objetos } \\
\text { del espacio (ropa y muebles), las obras } \\
\text { que había realizado en sesiones ante- } \\
\text { riores (la máscara, los dibujos de las } \\
\text { imágenes corporales intervenidos, los } \\
\text { escritos) y junto con su cuerpo y el del } \\
\text { investigador-interventor construyó una } \\
\text { escena en la que sintiera que estaba } \\
\text { presentando su proceso de cambio } \\
\text { vivido durante el desarrollo de las } \\
\text { sesiones y que le permitiera reconocer } \\
\text { las nuevas comprensiones y posiciona- } \\
\text { mientos que tiene frente a la vida y su } \\
\text { masculinidad. }\end{array}$ \\
\hline
\end{tabular}

Nota: Elaboración propia. 


\section{Muestreo y criterios de inclusión del participante}

Partiendo de los planteamientos de PérezLuco, Lagos, Mardones \& Sáez (2017), el muestreo fue intencionado -intrínseco- típico puesto que se realizó a partir de criterios de exclusión e inclusión preestablecidos en coherencia con la teoría previa del investigador-interventor (la cual se ha venido exponiendo en este texto) para buscar un caso que fuese demostrativo del fenómeno a partir de sus características.

Se definieron como criterios de inclusión para el participante que este se identificara como hombre, con una edad entre 20 a 30 años, que presentara o hubiese presentado conducta suicida, que tuviera un proceso psicoterapéutico (activo o no) de al menos tres sesiones y que no tuviese un riesgo alto de suicidio, o en caso de presentarlo haber realizado el reporte y la activación de rutas de atención correspondiente.

El participante cumplió con los criterios enunciados, ya que se identificaba como hombre, tenía 22 años y reportó que le gustaría morir a los 27 años y que a los 18 años había tenido un plan estructurado de suicidio. Asimismo, al momento de participar en la investigación se encontraba en un proceso de psicoterapia (inicialmente su motivo de consulta se relacionaba con rupturas amorosas y la muerte de su mascota) en el Servicio de Atención Psicológica de la Universidad Santo Tomás en Bogotá, misma institución en la que se realizó este proceso de investigación. Algunas características que no están relacionadas con los criterios de inclusión, pero que permiten caracterizar al participante, son que era soltero, homosexual, que tenía escasos recursos económicos, que vivía con su madre y que estaba formándose académicamente como psicólogo.

\section{Consideraciones éticas}

Esta investigación fue realizada en el marco de la formación de una maestría en psicología clínica y de la familia, en la que se brindan, a bajo costo, servicios de atención psicológica en un centro propio de la universidad, en el que los participantes tienen toda la libertad de formar parte o no de los procesos investigativos, sin recibir ningún incentivo. Debido a la naturaleza de la maestría, el proceso de investigación-intervención es supervisado por una profesional con mayor experiencia clínica desde una postura sistémica (la cual esta detallada en el apartado epistemológico). Asimismo, teniendo en cuenta el artículo 11 de la Resolución 008430 de 1993, por la cual se establecen las normas científicas, técnicas y administrativas para la investigación en salud, se definió que el nivel de riesgo para el participante de esta investigación es "Investigaciones con riesgo mayor que el mínimo"1. Se reconoció la sensibilidad de los temas que iban a ser abordados, así como las posibles movilizaciones emocionales que estos podían suponer. Así, para mitigar riesgos como el aumento de sensaciones de malestar y la agudización de síntomas relacionados con el suicidio, se contó con la formación del investigador-interventor como psicoterapeuta en el marco de la maestría, así como con el acompañamiento constante de la directora del trabajo de grado. Adicionalmente, otro factor que mitigó el riesgo fue que el participante en cuestión se encontraba simultáneamente en un proceso de psicoterapia. 
El consentimiento informado que fue diligenciado con el participante en la primera sesión del proceso respondió a lo expuesto por el artículo 15 y siguientes de la Resolución 008430 y se ajustó a los lineamientos de investigación-intervención de la Maestría en Psicología Clínica y de la Familia. Adicionalmente, el proyecto se acogió a la Ley 1.581 de 2012 (Hábeas Data), que aplica para el tratamiento de datos personales, lo cual fue informado al consultante a través del consentimiento informado². Las respuestas dadas en cada uno de los encuentros fueron codificadas usando otro nombre diferente al del participante y, por lo tanto, son anónimas. Toda la información que se obtuvo en el estudio es de carácter confidencial y solo será usada con fines académicos.

\section{Análisis de datos}

Para el análisis de la información obtenida en los diversos escenarios se optó por conectar elementos del análisis de contenidos por categorización (Díaz, 2018) con elementos del análisis estructural de contenidos (Rodríguez, 2008).

El análisis de contenidos por categorización, según Díaz (2018), consiste en la clasificación en categorías que buscan dar sentido a un cuerpo de información que ha sido recolectado. Bardín (2002, citado en Díaz, 2018) expone que las categorías son clases definidas conceptualmente que reúnen elementos de la información. Por su parte, el análisis estructural de contenido busca "la extracción del sentido que se encuentra en un soporte o discurso determinado" (Rodríguez, 2008 , p. 219). Este método postula que ningún elemento puede tener significado por sí mismo, por lo que se supone que existe una relación de oposición de dos o más elementos.
El sistema categoría es el elemento central del análisis de contenidos por categorización, por lo que a continuación se describirá el proceso de formulación de las categorías de este estudio, el cual es producto de la articulación entre diferentes propuestas conceptuales.

Del diálogo de los postulados de Estupiñán, González \& Serna (2006) sobre historias dominantes con los de Boal (2013) sobre opresión surgió la categoría de historias dominantes de opresión, que hace alusión a relatos totalizantes que, desde discursos opresivos, restringen las posibilidades del participante de ser hombre (masculinidad) o legitiman la muerte como única opción (suicidio).

Por otro lado, al conectar los planteamientos sobre memorias de Estupiñán, González y Serna (2006) con los de Martín-Baró (1990) sobre desideologización, se construyó la categoría de memorias de desideologización, las cuales son versiones por fuera de la historia dominante que cuestionan el sentido común que legitima una única forma de ser hombre (masculinidad) o la muerte como enemiga irreconciliable de la vida (suicidio).

Por último, al conectar los postulados de Latorre (2013) sobre historias alternativas con los de Ríos (2015) sobre re-existencia, emergió la categoría de historias alternativas de re-existencia, que fue comprendida como versiones novedosas que desafían las historias dominantes y generan nuevos órdenes de sentido para la persona, ofreciendo así oportunidades plurales de ser hombre (masculinidad) o de ver opciones más allá de la muerte (suicidio).

El procedimiento desarrollado para la construcción de resultados implicó que todos los escenarios de la investigación fueron grabados 
en audio y transcritos. Posterior a ello, a partir del sistema categorial definido en esta investigación, se formuló la matriz presentada en la
Tabla 2, a partir de la cual se realizó la organización y el análisis de la información.

Tabla 2. Matriz de análisis de la información.

\begin{tabular}{|l|l|l|}
\hline \multicolumn{2}{|c|}{ Masculinidad Suicidio } \\
\hline Historias de opresión & & \\
\hline Memorias de desideologización & & \\
\hline $\begin{array}{l}\text { Historias alternativas } \\
\text { de re-existencia }\end{array}$ & & \\
\hline
\end{tabular}

Nota: elaboración propia.

Una vez clasificada la información en la matriz de la Tabla 2, se llevó a cabo un análisis estructural de contenidos. Este proceso se da en dos fases: la primera constituye la construcción y descripción de unidades elementales de sentido y la segunda, la exploración de la relación y dinámica entre ellas.

De este modo, el análisis estructural de contenidos permitió profundizar en los elementos en oposición que configuraban el significado en el relato del participante, así como comprender el cambio en la relación de estos a lo largo del proceso de investigación. Es así como se llegó a formular una estructura de sentido que permitió ver con más claridad la conexión entre masculinidad y suicidio vivida por el participante, así como los atributos asociados a cada uno de estos elementos. Dicha estructura será expuesta en el apartado de resultados.

En síntesis, en un primer momento se acudió al análisis de contenidos por categorización para clasificar la información en un sistema categorial, definido desde la conceptualización del fenómeno realizada para esta investigación. Y posteriormente, desde el análisis estructural de contenidos, se formuló la estructura de sentido presente en el relato del participante, enriqueciendo así la categorización realizada.

\section{Resultados}

A partir del proceso de análisis descrito en el anterior apartado se organizaron las siguientes tres narrativas para exponer las comprensiones construidas en este proceso investigativo: 1) la vida sin cabida en la sociedad; 2) la vida legitimada por la muerte; y 3) la existencia querida. Adicionalmente, se presenta el lugar que tuvo el cuerpo como escenario de posibilidad durante el proceso, el cual fue un elemento emergente en el análisis realizado. Los fragmentos textuales se identifican por un código que permite ver el actor que lo dijo (A), que puede ser participante (P) o investigador-interventor (I), el número del encuentro (E) y el número de la intervención (I). 


\section{La vida sin cabida en la sociedad}

La conexión que existía en el relato del participante entre la masculinidad y el suicidio se configuraba desde una historia de opresión que restringía las posibilidades identitarias de este. Ello se recoge en el siguiente fragmento:

La masculinidad te encasilla tanto en lo que puede ser, pero la muerte pone fin a todas estas casillas, una vez mueres, ya estás muerto. [...] O sea, ya en la muerte ya no hay género, ya no hay necesidad de cumplir roles, de estereotipos de nada de eso, entonces es como que la muerte le pone fin a eso que siempre debiste ser. (AP E1 I176)

La masculinidad era vivida por el participante como una versión rígida, que aprendió de su madre y que luego le fue reafirmada por familiares y amigos. Según esta versión, el hombre "tiene que ser fuerte, responsable, que le gusten las mujeres; es como también un plus, competente, competitivo, eficaz ( $\mathrm{mmm})$, como que, controlado, debe controlar sus emociones y al mismo tiempo protector" (AP E2 I189). El participante no consideraba que cumpliera con dicha versión de hombre, especialmente por su sensibilidad y su homosexualidad. Esta sensibilidad era también vivida como problemática para el participante al interior de la comunidad LGBT, como lo expone en el siguiente fragmento:

Si no eres mejor dicho de cuerpo de gym, no llamas la atención de las otras personas, pero al mismo tiempo esa tensión está basada en el deseo sexual entonces... y yo soy alguien muy sentimental, entonces siento que es de mi condición que no encajo en la sociedad y donde se supone que debería encajar tampoco estoy encajando y no estoy encajando en la vida, o sea, yo pertenezco, yo no pertenezco a esta vida. Yo no pertenezco a este mundo. (AP E1 I142)

Esta experiencia de no encajar o pertenecer se configuró en un elemento central del malestar del participante, ya que no solo le reafirmaba que había algo malo con él por no tener las características del deber ser de un hombre o de un hombre homosexual, sino que reducía significativamente sus posibilidades de interacción y de existencia. El no cumplir con los mandatos sociales alrededor del deber ser suponía para el participante una experiencia de marginalidad y de profunda soledad.

Desde estas experiencias, el participante configuró una narrativa en la que la vida era una imposición de constante sufrimiento y frente a la cual solo podía escapar a través del suicidio, ya que, según él, "para la sociedad mi vida no tiene cabida" (AP E1 I53). Dentro de esta narrativa, el suicidio era considerado como una posibilidad de tener autonomía frente a la imposición de la vida y era visto como una forma de parar el sufrimiento proveniente de la censura y restricción por no cumplir con la versión hegemónica de masculinidad. Este sufrimiento llevaba al participante a enunciar que "es difícil pensar en el derecho de vivir, cuando para mí no lo veo, se me hace más fácil el derecho a morir, o sea, la vida que quiero vivir como es que... es como no, porque es morir" (AP E3 14).

A partir de lo anterior, se puede apreciar que la masculinidad se configuraba desde la tensión entre características censuradas y celebradas (es importante anotar que esta censura y celebración se da inicialmente desde ámbitos sociales, pero con el tiempo fue interiorizada por el participante), mientras que la existencia era configurada desde una tensión entre la vida vista como imposición y la muerte vista como decisión. Estos significados y tensiones configuraban un campo narrativo en relación con el suicidio y la masculinidad, que se puede apreciar con mayor detalle en la figura 1. 
Figura 1. Estructura de significado del relato del participante.

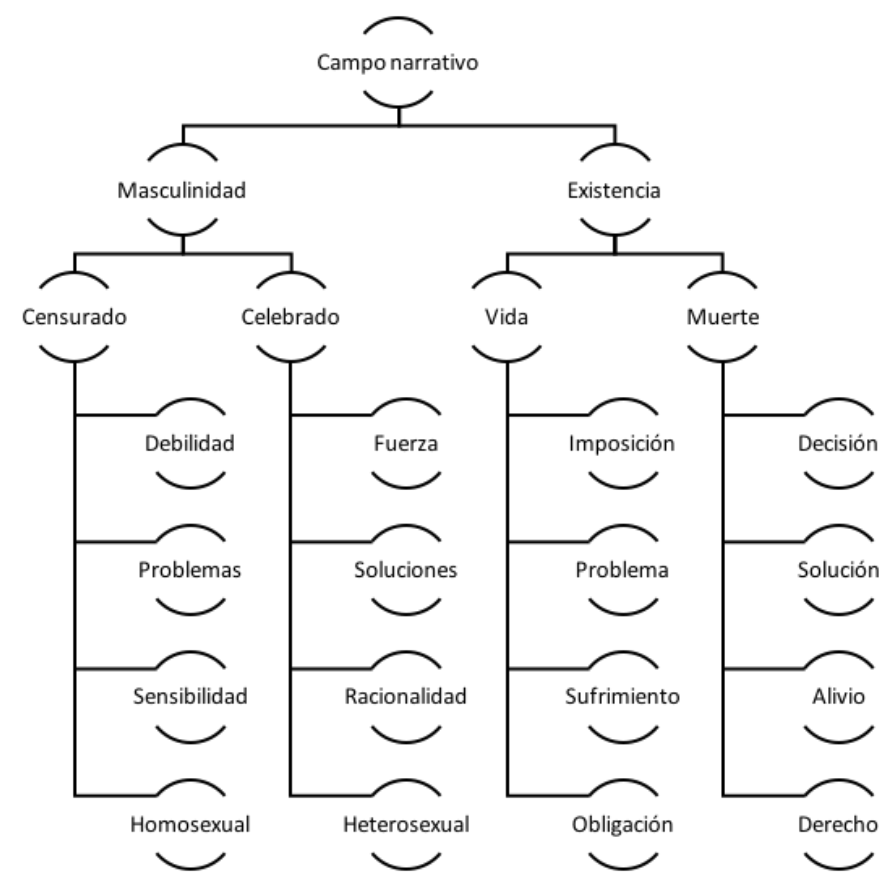

Nota: elaboración propia.

Desde el marco epistemológico de esta investigación la mirada sobre el observador configura un elemento central de la producción de conocimiento, por lo que es relevante exponer que, en lo referente a estas historias dominantes, el investigador-interventor logró conectarse con el participante desde las propias vivencias alrededor de la masculinidad y la censura de la homosexualidad. En él resonaban el sufrimiento y la imposibilidad que también en algún momento de su vida legitimaron la muerte sobre la vida. Esta sensibilidad del investigador-interventor fue movilizador para el proceso y favoreció los tratamientos dialógicos y reflexivos desde lecturas amplias y contextualizadas en torno al sufrimiento y las posibilidades de transformación de la masculinidad y la conexión con la vida.

\section{La vida legitimada por la muerte}

Las historias dominantes expuestas anteriormente estaban atravesadas por el sufrimiento y el deber ser, por lo que fue central en la apuesta psicoterapéutica la exploración del "querer ser" para favorecer la emergencia de nuevas posibilidades. Este "querer ser" se apreció en las memorias de desideologización, que cuestionaron las siguientes lógicas que legitimaban las historias dominantes: 1) la masculinidad como algo estático y rígido y 2) la enemistad entre muerte y vida.

Frente al primer cuestionamiento, el participante relató en un inicio que la masculinidad "no existe porque es que es una construcción social, entonces es cómo construimos lo que creemos 
que debería ser lo masculino y en función de eso pues todos orientamos eso" (AP E1 118); sin embargo, era en su relación con la masculinidad en la que se cimentaba su sufrimiento. Este cuestionamiento cobró fuerza en el transcurso de las sesiones, pero tomó una nueva forma al emerger una narrativa de la masculinidad más allá de una única versión, para vivir así su propia versión de masculinidad o, en sus propias palabras, "dejar de vivir en los cánones de la sociedad de pronto... o sea, como lograr ser un poco más libre" (AP E3 188).

La exploración que resultó en este cuestionamiento se dio a través de la construcción de imágenes corporales, las cuales permitieron que el participante imaginara nuevas posibilidades en otras formas de masculinidad. Fue a través de estas imágenes que se empieza a visibilizar, desde la conversación terapéutica, la influencia que tenía el "deber ser" en su vida, así como esos desenlaces excepcionales que lo invitaban a ver otros mundos posibles, que eran normalmente silenciados por la historia dominante.

El segundo cuestionamiento le permitió al participante desafiar la versión de que la muerte y la vida eran dos enemigos irreconciliables y el sentimiento de encontrar en la muerte, con la que sentía mayor cercanía, la posibilidad de encontrarle belleza a la vida y dejar de verla como una imposición, tal como se aprecia en el siguiente fragmento:

La vida es una flor que algún día morirá, algún día se marchitará y es lo que algunos autores ponen que es linda de la vida. Si nosotros viviéramos 500 años, no veríamos la vida como algo bello, la veríamos como algo tortuoso, algo que tendríamos que acabar sí o sí, pero es esa finitud lo que hace linda la vida. (AP E3 I178)
De este modo, las narrativas en torno a la enemistad entre muerte y vida se vieron enriquecidas por un ejercicio corporal en el que el participante, a través de su cuerpo y el cuerpo del investigador-interventor, elaboró imágenes corporales que le permitieron reconocer la resistencia y la resiliencia como elementos esenciales de su vida. Esto fue connotado nuevamente a través del equipo reflexivo al visibilizar las tensiones que vivía el participante entre el "deber ser" y el "querer ser". Estos dispositivos le permitieron a este tomar la cercanía que sentía con la muerte y ponerla al servicio de legitimar su vida.

Teniendo en cuenta la resonancia que tenía el investigador-interventor con la experiencia del participante, fue muy importante en estos ejercicios asumir deliberadamente una postura que invitara a la reflexión y no a imponer las reflexiones que el investigador-interventor ha construido a lo largo de su vida frente a la masculinidad y el suicidio, tanto de forma personal como profesional. Esto en sí mismo fue coherente con la búsqueda del querer ser por parte del participante, ya que si fuese el investigador-interventor quien definiera las versiones alternas alrededor de la masculinidad y el suicidio, este sería otro deber ser impuesto al participante, además que no recurriría a sus memorias y la potencia narrativa que estas tienen. Por último, es importante mencionar que los ejercicios corporales fueron centrales al momento de configurar una relación de confianza entre el investigador-interventor y el participante, al permitir la aparición del cuerpo del primero como recurso para el proceso de cambio. 


\section{La existencia querida}

Para que las memorias anteriormente enunciadas tomaran la potencia narrativa para consolidarse como historias alternativas fueron esenciales tres dispositivos: un monólogo, ejercicios escriturales de sesión a sesión y la elaboración de una escena teatral.

La elaboración y la declamación de un monólogo en el escenario investigativo le permitieron al participante enunciar esos nuevos lugares de re-existencia que logró construir a lo largo del proceso, desde la conexión entre el cuerpo y la palabra, y darle protagonismo a la voz del participante, la cual había sentido silenciada a lo largo de su vida. Este ejercicio y la conversación terapéutica alrededor del mismo permitieron dar un lugar protagónico a las versiones que cuestionaban y ofrecían posibilidades novedosas sobre la masculinidad y la existencia para el participante, dándoles así un carácter de historias alternativas.

Además de estas experiencias, es importante mencionar que se llevaron a cabo ejercicios escriturales durante todo el proceso, los cuales eran indicados al final de cada sesión y retomados al inicio de la siguiente. Estos estuvieron encaminados a visibilizar aquellas versiones que ofrecían posibilidades novedosas al participante, lo que favoreció que las reflexiones y posicionamientos construidos en el escenario investigativo se hicieran parte de la cotidianidad del participante y contribuyeran, con ello, a la apuesta del teatro del oprimido de llevar lo actuado en la escena teatral a la realidad social.

De este modo, las historias alternativas se vieron fortalecidas por un ejercicio performativo, en el que, a modo de ritual terapéutico, el participante retomó todas las producciones artísticas que había venido construyendo en el proceso investigativo-interventivo (la máscara, los dibujos, el monólogo y otros escritos adicionales) y junto con elementos presentes en el espacio, el cuerpo del investigador-interventor y su propio cuerpo construyó una escena teatral. Esta escena fue una oportunidad para que el participante recuperara el proceso de cambio que había vivido, al mismo tiempo que lo invitaba a asumir nuevas posturas existenciales desde dicho proceso. Asimismo, este dispositivo permitió conectar cuerpo y palabra, encarnando así las historias alternativas que se venían consolidando durante el proceso.

A partir de lo descrito, el participante logró consolidar nuevas versiones de sí mismo, en las que los elementos que antes eran vistos como deficitarios, como la homosexualidad, la sensibilidad y la cercanía con la muerte, se convirtieron en recursos para construir una existencia desde el "querer ser".

La homosexualidad empezó a ser narrada como una posibilidad de flexibilidad frente al género, ya que, "pues como soy homosexual, tengo ambos, como lo bueno de ambos mundos" (AP E2 186). Esto permitió una integración de lo que antes era visto por el consultante como masculino y femenino (en particular la conexión con sus emociones), lo que dio lugar a una nueva forma de vivir la sensibilidad en la que, para el participante, "el hecho de que sea sensible no quiere decir que no sea fuerte, puedo ser sensible y fuerte al mismo tiempo y aunque no lo parezca, puedo ser débil y fuerte al mismo tiempo" (AP E4 I318). Se dejaron de narrar los opuestos desde la contradicción y empezaron a ser narrados desde la complementariedad, siendo la relación entre la muerte 
y la vida el mejor ejemplo de esto, tal como se ve en el siguiente fragmento:

Y si yo quiero vivir pensando constantemente en la muerte, queriendo tenerla como mi amiga, como esa oscuridad que me ayuda a ver la luz, quiero vivir así, quiero ser quien yo soy y aunque sí tenga que someterme a unas cosas, quiero que aunque sea en ese camino, quiero que ese camino que otros pintaron que debería seguir, quiero caminarlo yo [...] estaré siguiendo ese camino, pero lo estaré siguiendo a mi manera. (AP E4 I322)

La integración dialógica de opuestos le permitió al participante configurar nuevos órdenes de sentido, en los que logró posicionarse de manera crítica, creativa y autónoma frente a las versiones hegemónicas de la masculinidad y la vida. Esto le permitió conectarse con la libertad y las nuevas posibilidades, desde una postura en la que "no pienso en la vida que quiero vivir, sino en la existencia que quiero ser" (AP E4 I330).

Es importante mencionar que el proceso de cambio descrito supuso movilizaciones en las propias comprensiones del investigador-interventor sobre su masculinidad y su vida. Estas movilizaciones abrieron posibilidades al momento de poner en escena los dispositivos terapéuticos, ya que estos se vieron enriquecidos por posturas de curiosidad y humildad por parte del investigador-interventor, quien reconoció que su experticia no estaba centrada tanto en el contenido de las reflexiones, sino en los procesos conversacionales que favorecieran al participante generar sus propias versiones frente a la masculinidad y la vida. Esto permitió que se configurara una relación desde la confianza y el reconocimiento mutuo entre investigador-interventor y participante, en la que la voz del primero no pesaba sobre la del segundo, sino que, por el contrario, el protagonismo de la voz del participante le invitó a reconocerse desde la libertad y la autonomía.

\section{El cuerpo como escenario de lo posible}

El cuerpo se convirtió en el escenario para explorar nuevas posibilidades en la configuración narrativa del participante. Este permitió ir más allá de la racionalidad instalada desde la versión rígida de la masculinidad y dar lugar a la exploración y la expresión de las emociones que esta suponía en la vida del participante. Emociones marcadas por el malestar, el sufrimiento y el cansancio, por tener que sostener algo que sentía como ajeno e impuesto. La máscara elaborada en el primer escenario y, en especial, las imágenes corporales del segundo pusieron a las emociones en escena más allá de las palabras, permitiendo así un diálogo entre lo dicho y lo encarnado.

Esto se puede apreciar en el siguiente fragmento de la conversación sobre una de las imágenes corporales realizadas en el segundo encuentro sobre la versión del deber ser de la masculinidad:

Participante: Quiero quitarme este peso, porque mantener esta pose es muy agotador, es horrible, mis piernas no se sienten cansadas, pero mis brazos y el pecho me pesa para respirar, es horrible esta sensación. (AP E2 I170)

Investigador-interventor: Ok, ¿cómo se ha vivido esto en tu vida? Valga la redundancia. (AI-I E2 I171)

Participante: Mantener una forma, o sea, cuando me dijiste esto de mantenerlo, sentí una presión como "juemadre, me voy a ahogar, no voy a poder", y es el sentido de que siempre debo ser así, así me esté cansando, así me esté muriendo, debes estar así. (AP E2 I172) 
El cuerpo no solo permitió explorar las historias dominantes, sino que encontrar grietas en la mismas que invitaron al participante a asumir posicionamientos vitales novedosos desde el cuestionamiento de las lógicas que legitimaban y sostenían su sufrimiento. Asimismo, el poder desarrollar ejercicios como escribir y actuar un monólogo en el que exponía sus nuevos posicionamientos vitales; y diseñar y actuar una escena sobre las transformaciones vividas, invitaron al participante a encarnar estas narrativas novedosas que se fueron dando durante el proceso.

El siguiente fragmento de la conversación sostenida en el encuentro de cierre sobre los cambios que vivió el participante y las emociones que estos le generan permite observar lo dicho:

Investigador-interventor: Ok, dónde... ¿dónde se siente el orgullo en tu cuerpo?. (Al-I E5 I74)

Participante: Lo siento en el pecho, como... como un sentimiento que nace ahí y se expande por el resto de mi cuerpo. (AP E5 I75)

Investigador-interventor: ¿Y este orgullo con qué está relacionado?. (AI-I E5 I76)

Participante: Con mi proceso, veo como una línea del tiempo, como una historia donde llegué cubriéndome la cabeza, donde no veía o no mostraba lo que yo era y por medio de todo este trabajo, esta obra, todos los escritos, todos estos trabajos ahora muestro quién soy, pero ahora sostengo algo en mis manos y este algo tal vez no sepa para qué me sirve, o sí sé para qué me sirve, tal vez no he comenzado a dibujarlo, pero es el hecho de que ahora tengo más colores, cuando entré tenía la sensación de un vacío cuando pensaba en la muerte, pero con esto siento que ahora puedo dibujar la muer... puedo seguir viendo la muerte como una vieja amiga, pero puedo colorearla de diferentes maneras. (AP E5 I77)
El cuerpo fue el territorio relacional en el que se tejieron las conversaciones y se fortalecieron las historias alternativas, ya que pudieron ser encarnadas y llevadas a la cotidianidad del participante, permitiéndole mayor libertad, autonomía y conexión consigo mismo. Adicionalmente, el cuerpo permitió fortalecer la relación entre el investigador-interventor y el participante, ya que el cuerpo del investigador-interventor también se puso en escena como un recurso para el proceso de cambio, tal como se puede ver en la siguiente intervención del investigador-interventor en el tercer encuentro: "entonces la idea es que usando mi cuerpo y el tuyo armemos una primera imagen de lo que, para ti, en tu vida, ha sido la resistencia" (Al-I E3 I31).

\section{Discusión}

En la narrativa del participante, la conexión entre masculinidad y suicidio se encontraba en el sufrimiento de sentir que "para la sociedad mi vida no tiene cabida" (AP E1 I53). Esta narrativa se configuraba desde la experiencia de censura de sí mismo, la cual podría conectarse con un proceso de estigmatización internalizada, que González (2019) explora en diagnósticos de salud mental, pero cuya comprensión puede ser llevada a otras experiencias de diferencia, como lo son, en este caso, la homosexualidad y el no cumplimiento de la masculinidad hegemónica. De acuerdo con esta autora la estigmatización internalizada es un proceso dinámico en que la persona no solo asume las creencias negativas que se tienen en su contexto sociocultural frente a cierto grupo de personas, sino que al pertenecer a dicho grupo incorpora dichas creencias negativas a su propia identidad. Esta estigmati- 
zación internalizada en el participante lo llevaba a censurar su propia diferencia, así como a considerar que no iba a encontrar un espacio social al cual pertenecer, por lo que a partir de este sufrimiento la vida se narraba como una imposición a la que solo se podía escapar a través del suicidio.

Retomando los planteamientos de Butler (2010), se puede apreciar cómo la existencia del participante no es aprehendida por la sociedad como vida, al no cumplir las normas que socialmente definen lo que es y no es una vida digna. Según esta autora, la ontología corporal (porque el cuerpo no se tiene, se es) está atravesada por lógicas que se encuentran en las relaciones, como el caso del participante con su madre, algunos familiares, amigos y parejas, que definen lo que es una vida digna y lo que no lo es. Estas lógicas están articuladas alrededor de lo que Pérez-Orosco (2014) enuncia como modelo de sujeto BBVAh (sujeto burgués, varón, adulto, con funcionalidad normativa y heterosexual), al cual, desde lógicas patriarcales y capitalistas, se le da un lugar privilegiado en la sociedad, en que los poderes sociales, políticos y económicos le pertenecen, mientras que quienes no cumplen con este modelo quedan destinados a la periferia o, en palabras, de Butler (2010), a la precariedad.

Esta periferia a la que quedan destinados muchos sujetos es la que genera tanto sufrimiento en el participante, quien la vive como una imposibilidad, en un no-lugar, en el que, según Ceballos-Espinoza (2016), se encuentran los suicidas. De acuerdo con este autor, este no-lugar resulta inhabitable, ya que no ofrece oportunidades ni a la identidad ni a la relación con otros, lo que lo lleva a caracterizarse por la soledad y por la necesidad de tener un espacio que no encuentra. Estas emociones resuenan con las narrativas iniciales del participante de sentir que sus relaciones se veían amenazadas por no cumplir con estos mandatos o que la muerte era la única posibilidad para escapar de la rigidez de la masculinidad que lo dejaba sin lugar de existencia.

Estos elementos eran los que configuraban la conexión de la masculinidad y el suicidio en lo que Latorre (2013) enuncia como una historia dominante, ya que totalizaba la identidad del participante, aprisionándolo en las conclusiones negativas de quien es (o para ser más precisos, en este caso, de quien no era, a la luz del modelo BBVAh), adquiriendo un carácter de verdad frente al cual pareciese no tener posibilidades de negociación ni cuestionamiento, dejando así el suicidio como única posibilidad.

Teniendo en cuenta lo anterior y la ontología corporal (Butler, 2010) en la que se articulan las lógicas que suponían el sufrimiento del participante, tiene sentido el haberle dado un lugar central al cuerpo dentro del proceso de cambio. El cuerpo, tal como lo expone Castañeda (2011), es un territorio de existencia que va más allá de una posesión y se conecta profundamente con quien somos. El cuerpo fue una entrada a lo sensible, a aquello que históricamente se había silenciado desde las versiones rígidas de la masculinidad y la vida, y en donde la experiencia hablaba con más fuerza que la censura y la restricción. El cuerpo permitió encarnar las narrativas, especialmente aquellas que se fueron co-construyendo en las sesiones de la investigación, para acceder a aquello que está por fuera de la palabra o, como lo llama Ríos (2015), la reflexividad en la piel. 
Para acceder a esta reflexividad en la piel fue clave el diálogo entre las tres hipótesis del arcoíris del deseo de Boal (2013) y las tres apuestas de la terapia narrativa de Payne (2002). A continuación se presentan dichas articulaciones.

La osmosis y el tener en cuenta los aspectos sociales y políticos de las narrativas permitieron generar un espacio conversacional en el que se cuestionaba el patriarcado y en el que el participante logró asumir una postura crítica frente a esta lógica que atravesaba sus narrativas. Si bien el participante traía en su discurso la noción de que el género se construye socialmente, a través de los dispositivos diseñados para la investigación-intervención esa afirmación se llenó de sentido al reconocer cómo algunas versiones dominantes de la masculinidad orientaban su vida y la configuración relacional e histórica que estas habían tenido en ella.

La inducción analógica y la indagación por la influencia relativa supusieron una oportunidad de darle más fuerza a los cuestionamientos del participante al explorar nuevas formas de ver la masculinidad y la vida. La versión dominante de la masculinidad y lo que suponía para la vida del participante empezó a ser vista como una versión entre muchas otras posibles. Adicionalmente, los diferentes dispositivos le permitieron reconocer que posicionarse de manera crítica y creativa frente a las versiones dominantes que habían orientado su vida era una posibilidad.

$\mathrm{Y}$, por último, la metaxis y la deconstrucción de desenlaces inesperados fortalecieron a las narrativas que iban emergiendo y que le ofrecían nuevas posibilidades identitarias al participante, invitándole a llevar lo que actuaba en los escenarios de la investigación a su cotidianidad y relaciones interpersonales.
Esta articulación supuso una apuesta constante desde los diferentes dispositivos para recuperar en los escenarios de investigación aquellas experiencias del participante que lo invitaban a ver que otras formas de ser hombre y conectarse con la vida eran posibles. Asimismo, otra apuesta fundamental desde esta articulación fue que este, a través de los ejercicios físicos y artísticos, conectara el cuerpo y la palabra y, lo más importante, que llevara las comprensiones construidas en los escenarios de investigación a la cotidianidad.

Esto favoreció la emergencia de historias alternativas de re-existencia conectadas con el poder vivir desde el querer ser y no desde el deber ser. La muerte dejó de verse como un escape a la vida y empezó ser reconocida como una posibilidad de legitimarla, ampliando así las posibilidades que le permitieran un lugar de existencia en el que se viabilizaran otras formas posibles de ser hombre por fuera del modelo de sujeto BBVAh.

Un elemento clave para acceder a estas historias alternativas fue la desideologización (Martín-Baró, 1990) que supuso cuestionar el heteropatriarcado que enuncia una sola posibilidad de ser hombre, así como la noción de que la vida y la muerte son enemigas irreconciliables. La desideologización le abrió la posibilidad al participante de configurar nuevas versiones de sí mismo en las que integró dialógicamente los opuestos presentes en la masculinidad y la existencia. Estas historias alternativas configuradas por él se conectan con la re-existencia (Ríos, 2015), ya que supusieron actos de creación que lejos de ser una huida frente a la vida, la reafirmaron a través del acto creativo que decodificó las líneas de la opresión y abrió un vacío lógico, en el que la integración de 
opuestos no solo fue posible, sino que se configuró en nuevos lugares de existencia.

Asimismo, es importante anotar que la desideologización y la re-existencia permitieron ampliar las comprensiones que desde los conceptos de memorias e historias alternativas se tiene del proceso de cambio. Por un lado, la articulación de memoria y desideologización invitó a ver cómo la exploración de versiones periféricas se ve fortalecida cuando se desenmascaran los sentidos comunes, en este caso, el patriarcado, que legitiman las versiones dominantes. Esto se puede apreciar en el reconocimiento que tuvo el participante de cómo se legitimaba en sus relacionas esta versión única de masculinidad, así como el empezar a construir nuevos sentidos alrededor de los cuestionamientos sobre la naturaleza determinista del género. Adicionalmente, esta articulación reafirma el sentido político que implica cuestionar desde las memorias las versiones dominantes. Por otro lado, el articular re-existencia con historia alternativa permitió ver cómo estas versiones novedosas ganan vigencia y potencia en el relato identitario cuando se logran crear nuevos órdenes de sentido que van más allá de la resistencia, en los que los opuestos se integran y se asumen posicionamientos creativos frente a la opresión. Esto fue visible en la posibilidad que construyó el participante de ser su propia versión de hombre y utilizar la cercanía con la muerte como una posibilidad para conectarse con la vida.

En constraste con las investigaciones de Rosado, García, Alfeo \& Rodríguez (2014), Pirkis, Spittal, Keogh, Mousaferiadis \& Currier (2017), Apesoa-Verano, Barker \& Hinton (2018), Lyberg, Haavind \& Dieserud (2018) y Jordan \& Chandler (2019), aquí se opta por una mirada generativa de la masculinidad, desde la cual se reconoce que ciertas versiones hegemónicas pueden estar conectadas con el suicidio, pero que construir nuevas versiones alrededor de la masculinidad puede convertirse en una oportunidad y recurso para favorecer nuevas conexiones con la vida. Asimismo, el marco narrativo desde el que se realizó esta investigación ofrece una mirada compleja y relacional del suicidio, en la que tener en cuenta el género ofrece novedosas oportunidades comprensivas e interventivas.

En lo referente al teatro del oprimido se reafirman las posibilidades que brinda para la transformación de las relaciones de opresión que configuran el género, tal como lo exponen las investigaciones de Madurga \& Serra (2016), Spychaj (2014), Porras (2016), Parra (2015), Biggus (2017) y Cárdenas y Pozo (2018). Sin embargo, la articulación realizada con el teatro del oprimido y con los conceptos de desideologización y re-existencia permite ampliar las posibilidades comprensivas e interventivas de este dispositivo, así como ver la potencia que tiene en escenarios de intervención en salud mental.

\section{Conclusiones}

En el caso estudiado en esta investigación-intervención, el suicidio era narrado por el participante como la única opción para escapar a la rigidez de las versiones hegemónicas de la masculinidad, desde las cuales sentía que le eran censuradas varias de sus características, especialmente su sensibilidad y homosexualidad. Asimismo, es importante resaltar que a partir de estas narrativas el participante equiparaba la vida con una imposición de sufrimiento, lo que legitimaba aún más a la muerte como opción sobre la vida. 
La lógica en la que se cimentaba este sufrimiento se daba desde centros y periferias en las que solo se puede ser hombre si se cumple con características como la heterosexualidad, la racionalidad, la autosuficiencia, etc., así como solamente se puede estar del lado de la vida o del lado de la muerte. Frente a esta lógica, el análisis de contenidos por categorización y el análisis estructural de contenidos fueron importantes para delimitar y develar los opuestos que estructuraban el sentido construido a partir de la historia dominante en el relato del participante. Estos análisis permitieron ver cómo el cambio no se daba al generar nuevos opuestos que dieran nuevos sentidos, sino al encontrar nuevos sentidos en la integración de los opuestos ya existentes.

Desde la movilización vivida por el participante se puede ver la potencia que tiene la articulación del teatro del oprimido y la terapia narrativa, ya que favoreció que las historias alternativas fueran encarnadas y llevadas a las relaciones y cotidianidad del participante, dándoles mayor fuerza en sus procesos de configuración identitaria. El cuerpo se convirtió en una posibilidad de existir de maneras novedosas y recuperar aquellos elementos que fortalecieron la historia alternativa del participante.

Asimismo, las categorías de desideologización y re-existencia fueron claves para comprender el proceso de cambio. La primera permitió ver cómo se dieron cuestionamientos a la lógica del patriarcado que legitimaba la opresión en la vida del participante, mientras que la segunda permitió aproximarse a la creación de nuevos órdenes de sentido realizada por este, en los que no niega los opuestos, sino que los pone a conversar para crear lugares existenciales novedosos que le generan mayor autonomía y libertad.
La articulación entre el teatro del oprimido y la terapia narrativa brinda claves metodológicas para procesos de acompañamiento psicoterapéutico con casos que tengan motivos de consulta similares, e incluso da pistas para procesos de prevención del suicidio en que el punto de partida sea explorar y transformar las versiones relacionadas con el género. Esta articulación también supone una invitación a incluir con mayor protagonismo el cuerpo en los escenarios de intervención, reconociendo el lugar central que tiene en la configuración identitaria y las posibilidades de exploración y fortalecimiento de historias alternativas.

Este estudio invita a admitir la importancia que tiene el género, en este caso la masculinidad, en el abordaje del suicido, ya que ofrece nuevos focos conversacionales que pueden fortalecer los procesos de prevención, evaluación e intervención. Adicionalmente, el marco comprensivo de las narrativas tiene la capacidad de explicar diversos fenómenos sociales, en este caso la conexión entre masculinidad y suicidio, desde una mirada novedosa que conecta la particularidad del relato de la persona con las configuraciones discursivas y prácticas sociales que atraviesan los cuerpos y que socialmente definen unas vidas como más dignas que otras. A partir de esta mirada es necesario asumir un compromiso ético-político que contribuya a transformar, desde los diferentes escenarios de investigación e intervención, dichas configuraciones para ampliar las posibilidades de libertad y autonomía de aquellas personas y colectivos que históricamente han sido oprimidos y segregados.

Por último, es importante resaltar que esta investigación puede convertirse en un punto de partida para seguir explorando la potencia del teatro del oprimido en los escenarios de inter- 
vención en salud mental, no solo individuales, como se optó en esta investigación, sino colectivos. Asimismo, si bien no fue un criterio de inclusión de este estudio, la homosexualidad del participante fue un elemento relevante para el análisis, por lo que este trabajo invita a seguir explorando cómo se da la relación entre masculinidad y suicidio teniendo en cuenta otras interseccionalidades, como las de clase social, etnia o condiciones de discapacidad, incluso explorando si esta relación entre masculinidad y suicidio se vive diferencialmente para hombres heterosexuales. Es a partir de lo anterior que se destacan algunas preguntas que pueden resultar interesantes para futuras investigaciones: 1) ¿cómo se articula el teatro del oprimido y la terapia narrativa en escenarios colectivos para contribuir a la transformación de la relación entre masculinidad y suicidio?, y 2) ¿cómo se da la conexión entre masculinidad y suicidio en el caso de hombres heterosexuales? (esta última pregunta podría formularse con cualquier otro tipo de interseccionalidad, como raza, clase, etnia, condición de discapacidad, etc.).

\section{Notas}

${ }^{1}$ Resolución № 8430, 4 de octubre de 1993, por la cual se establecen las normas científicas, técnicas y administrativas para la investigación en salud. Congreso de la República.

\section{Referencias bibliográficas}

Achinte, A. (2009). Pedagogía de la re-existencia: Artistas indígenas y afrocolombianos. Popayán: Universidad del Cauca.

Agudelo-Bedoya, M. E. \& Estrada-Arango, P. (2012). Constructivismo y construccionismo social: Algunos puntos comunes y algunas divergencias de estas corrientes teóricas. Prospectiva. Revista de Trabajo Social e Intervención Social, 17, 353-378.

Andrade, J. A. (2016). El suicidio: Un fenómeno complejo: Aproximaciones desde la teoría de la complejidad. En Andrade, J. A. \& Calle, D. (Eds.), Ensayos académicos en torno al suicidio (pp. 11-36). Santiago de Cali: Fundación Participar IPS.

Apesoa-Varano, E., Barker, J. \& Hinton, L. (2018). "If you were like me, you would consider it too": Suicide, older men and masculinity. Society and Mental Health, 8(2), 157-173.

Baden, M. S. \& Wimpenny, K. (2014). A practical guide to artsrelated research. Róterdam: Sense.

Bardin, L. (2002). El análisis de contenido. Madrid: Ediciones Akal.

Bateson, G. (1972) Pasos hacia una ecología de la mente. Argentina: Ediciones Lohlé

Biggus, L. (2017). La resistencia cultural a través del teatro de las oprimidas para la cultivación de la subjetividad de la mujer en un contexto de violencia de género: Un estudio de caso del Colectivo de Mujeres Osadía. Independent Study Project (ISP), Collection 2539
${ }^{2}$ Ley Estatutaria № 1581, 17 de octubre de 2012, por la cual se dictan disposiciones generales para la protección de datos personales. Congreso de la República.

Boal, A. (2013). El arco iris del deseo: Del teatro experimental a la terapia. Barcelona: Alba.

Budge, S. L. \& Moradi, B. (2018). Attending to gender in psychotherapy: Understanding and incorporating systems of power. Journal of Clinical Psychology, 74(11), 2014-2027.

Butler, J. (2010). Marcos de guerra: Las vidas Iloradas. Barcelona: Paidós.

Camacho, J. (2006). Panorámica de la terapia sistémica. Recuperado de http://www. fundacionforo.com/pdfs/archivo33. pdf.

Carabí, À. \& Armengol, J. M. (2015). Introducción. En Carabí, À. \& Armengol, J. M. (Eds.), Masculinidades alternativas en el mundo de hoy. Barcelona: Icaria.

Cárdenas, J. \& Pozo, K. E. (2018). Sistematización del proceso de sensibilización sobre violencia de género basado en el teatro del oprimido realizado por el equipo de promoción de derechos de los Centros de Equidad y Justicia del Distrito Metropolitano de Quito, de febrero a julio 2107. (Tesis inédita de grado). Universidad Politécnica Salesiana de Ecuador.

Castañeda, M. D. (2011). El cuerpo grita lo que la boca calla. Razón y palabra, 77, 1-11.

Ceballos-Espinoza, F. (2016). Mensajes póstumos y discurso suicida: Hacia la teoría del no-lugar suicida. Gaceta de Psiquiatría 
Universitaria, 12(1), 35-41.

Charry, V. \& Pedraza, S. (2019). Género, hombres y corporeidad: Un estudio narrativo complejo. (Tesis inédita de maestría en psicología clínica y de la familia). Universidad Santo Tómas, Bogotá.

Connell, R. (1995). La organización social de la masculinidad. En Valdés, T \& Olavarría, J. (Eds.), Masculinidad/es: poder y crisis (pp. 3148). Santiago de Chile: ISIS Internacional, Facultad Latinoamericana de Ciencias Sociales.

California Press.

(2005). Masculinities ( $2^{\underline{a}}$ ed.). Berkeley: University of

Díaz, C. (2018). Investigación cualitativa y análisis de contenido temático. Orientación intelectual de revista Universum. Revista General de Información y Documentación, 28(1), 119-142.

Díaz, R., Rivera, S. \& Wolfgang, P. (2012). Masculinidad-feminidad y salud mental. Persona, 15, 137-157.

Durkheim, É. (2012). El suicidio ( $2^{\mathrm{a}}$ ed.). Madrid: Akal.

Estupiñán, J. González, O. \& Serna, A. (2006). Historias y narrativas familiares en diversidad de contextos. Bogotá: Universidad Santo Tomás.

Fonseca, C. \& Quintero, M. L. (2009). La teoría queer: la deconstrucción de las sexualidades periféricas. Sociológica, 24(69), 43-60.

García, L. (2015). Nuevas masculinidades: Discursos y prácticas de resistencia al patriarcado. (Tesis inédita de maestría). Facultad Latinoamericana de Ciencias Sociales, Quito.

Gergen, K. J. (2007). Construccionismo social: Aportes para el debate y la práctica. Bogotá: Universidad de Los Andes, Centro de Estudios Socioculturales e Internacionales.

González, F. (2006). Investigación cualitativa y subjetividad. Guatemala: Oficina de Derechos Humanos del Arzobispado de Guatemala.

González, S. (2019). Estigma y salud mental: Estigma internalizado. (Tesis inédita de doctorado). Universidad Complutense de Madrid, Madrid.

Horlacher, S. (2015). Configuring masculinity. En Horlacher, S. (Ed.), Configuring masculinity in theory and literary practice (pp. 1-10). Leiden: Brill.

Hunt, K. (2019). Una persona se suicida cada 40 segundos, según la OMS. CNN, 9 de septiembre. Recuperado de https:// cnnespanol.cnn.com/2019/09/09/una-persona-se-suicida-cada-40segundos-segun-la-oms/

Infantes, A. T. \& Delgado, A. D. (2011). El significado de la masculinidad para el análisis social. Nuevas Tendencias en Antropología, 2, 80-103.

Instituto Nacional de Medicina Legal y Ciencias Forenses (2019). Boletín Estadístico Mensual, diciembre. Recuperado de https:// www.medicinalegal.gov.co/documents/20143/349426/diciembre-2019. pdf/320ad04c-7c85-287f-804a-a49b1031d9f3

Jabeen, S. (2018). Concept of masculinity in men. Annals of Social Sciences \& Management Studies (ASM), 1(4), 1-5.

Jordan, A. \& Chandler, A. (2019). Crisis, what crisis? A feminist analysis of discourse on masculinities and suicide. Journal of Gender,
28(4), 462-474.

Keeney, B. (1987). Estética del cambio. Barcelona, España: Paidós Klonsky, E. D., May, A. M. \& Saffer, B. Y. (2016). Suicide, suicide attempts, and suicidal ideation. Annual Review of Clinical Psychology, 12, 307-330.

Latorre, í. (2013). Terapia narrativa: Algunas ideas y prácticas. En García Martínez, F. E. (Comp.), Terapia sistémica breve: Fundamentos y aplicaciones (pp. 97-142). Santiago de Chile: RIL.

Lemus, T. \& Vargas, A. (2016). Reconfiguración narrativa en familias con experiencia de suicidio: Un abordaje desde las prácticas en salud pública en el departamento de Casanare. (Tesis inédita de maestría en psicología clínica y de la familia). Universidad Santo Tomás, Bogotá.

Llanos, K. \& Saavedra, L. (2019). Transgénero: Transitando en la identidad narrativa del género. (Tesis de maestría en psicología clínica y de la familia). Universidad Santo Tómas, Bogotá.

Londoño, M., Mendivelso, A. \& Rodríguez, S. (2017). Subjetividad como autoorganización vincular: Perspectiva de género y generatividad con mujeres adolescentes. (Tesis inédita de maestría en psicología clínica y de la familia). Universidad Santo Tómas, Bogotá.

Lyberg, M., Haavind, H. \& Dieserud, G. (2018). Young men, masculinities, and suicide. Archives of Suicide Research, 22(2), 327-343.

Madurga, A. C. \& Serra, J. C. (2016). El potencial del teatro foro como herramienta de investigación. Athenea Digital. Revista de Pensamiento e Investigación Social, 16(1), 189-209.

Maguen, S., Ren, L., Bosch, J. O., Marmar, C. R. \& Seal, K. H. (2010). Gender differences in mental health diagnoses among Iraq and Afghanistan veterans enrolled in veterans affairs health care. American Journal of Public Health, 100(12), 2450-2456.

Maldonado, C. E. \& Gómez, N. A. (2010). El mundo de las ciencias de la complejidad: Un estado del arte. Documentos de Investigación, Facultad de Administración, Universidad del Rosario, Bogotá.

Mancilla, R. (2011). Introduction to sociocybernetics (Part 1): Third order cybernetics and a basic framework for society. Journal of Sociocybernetics, 42(9), 35-56.

(2013). Introduction to sociocybernetics (Part 3): Fourth order cybernetics. Journal of Sociocybernetics, 44(11), 47-73.

Martín-Baró, I. (1990). La desideologización como aporte de la psicología social al desarrollo de la democracia en Latinoamérica. Iztapalapa. Revista de Ciencias Sociales y Humanidades, 10(20), 101-108.

Osorio, S. N. (2012). Ciencias de la complejidad, pensamiento complejo y conocimiento transdisciplinar: Re-pensando la Humana Coditio en un mundo tecnocientífico. En Corbí, M. (Coord.), La crisis axiológica raíz de todas las crisis que sufre nuestro mundo. Cómo manejarnos con ella (pp. 223-264). 8ํㅡㄹ Enentro Internacional CETR. Barcelona: Bubok.

Paguey, J. (2017). La aportación del feminismo en la psicoterapia con mujeres: Interiorización personal subjetiva del feminismo en la praxis cotidiana como psicóloga. En Blanco, M. \& Sainz, C. (Eds.), Investigación joven con perspectiva de género II. Madrid: Instituto 
de Estudios de Género, Universidad Carlos III de Madrid.

Parra, A. (2015). Juegos de empoderamiento: Teatro del oprimido contra la violencia de género. (Tesis inédita de maestría). Universidad Autónoma de Barcelona, Barcelona.

Payne, M. (2002). Terapia narrativa: Una introducción para profesionales. Madrid: Paidós.

Pérez-Luco Arenas, R., Lagos, L., Mardones, R. \& Sáez, F. (2017). Taxonomía de diseños y muestreo en investigación cualitativa: Un intento de síntesis entre las aproximaciones teórica y emergente. Ámbitos. Revista Internacional de Comunicación, 39.

Pérez-Orosco, A. (2014). Subversión feminista de la economía: Aportes para un debate sobre el conflicto capital-vida. Madrid: Traficantes de Sueños.

Pirkis, J., Spittal, M., Keogh, L., Mousaferiadis, T. \& Currier, D. (2017). Masculinity and suicidal thinking. Social Psychiatry and Psychiatric Epidemiology, 52(3), 319-327.

Planas, M. (2018). Configuración identitaria, construcciones sociales desde la perspectiva de género, estética y corporalidad en jóvenes que ejercen el "prepaguismo". (Tesis inédita de maestría en psicología clínica y de la familia). Universidad Santo Tomás, Bogotá.

Porras, E. A. (2016). Sistematización del proceso de formación en prevención de la violencia de género y nuevas masculinidades con jóvenes hombres de 15 a 25 años del proyecto "Yo construyo mi masculinidad" de la ciudad de Quito, de octubre 2015 a marzo 2016. (Tesis inédita de grado). Universidad Politécnica Salesiana de Ecuador.

Ríos, C. (2015). Re-existencia: La dimensión política de la estética de la existencia. El Banquete de los Dioses, 3(5), 221-252.
Rodríguez, D. (2017). Self y experiencia de suicidio en la ecología joven, familia y escuela. (Tesis inédita de maestría en psicología clínica y de la familia). Universidad Santo Tómas, Bogotá.

Rodríguez, G., Gil, J. \& García, E. (2006). Estudio de casos. En Alonso, A. (Ed.), Estudio de caso: Selección de lecturas. La Habana: Félix Varela.

Rodríguez, M. (2008). Análisis estructural de contenidos: Herramientas básicas para su comprensión y uso. Perspectivas, 19, 217-241.

Rosado, M., García, F., Alfeo, J. \& Rodríguez, J. (2014). El suicidio masculino: Una cuestión de género. Prisma Social. Revista de Investigación Social, 13, 433-492.

Scandar, M. G. (2014). El uso del estudio de casos en la investigación en psicoterapia. Psicodebate, 14(1), 69-84.

Schermer, T. W. (2013). The story of manhood: Using a narrative approach to facilitate unique constructions of masculinity. Journal of Creativity in Mental Health, 8(2), 136-150.

Spychaj, M. A. (2014). El teatro del oprimido/a desde un enfoque de género. Dos casos de estudio: Madalena-Teatro das Oprimidas y Grupo Marias do Brasil. (Tesis inédita de maestría). Universidad de Granada, Granada.

Vila, F. (2018). La invención de la subjetividad. En Climent Clemente, M. T. \& Carmona Osorio, M. (Eds.), Transpsiquiatría: Abordajes queer en salud mental (pp. 18-25). Madrid: Asociación Española de Neuropsiquiatría.

White, M. K. (2007). Maps of narrative practice. Nueva York: WW Norton \& Company. 